04

\title{
Запись поляризационных голограмм в пленках сополимеров 4-((2-бром-4-нитрофенил)диазенил)фенилметакрилата
}

\author{
() Н.А. Давиденко ${ }^{1}$, И.И. Давиденко ${ }^{1}$, В.В. Кравченко ${ }^{2}$, А.И. Маринин ${ }^{3}$, Е.В. Мокринская ${ }^{1}$, \\ В.А. Павлов ${ }^{1}$, В.В. Тарасенко ${ }^{1}$, Н.Г. Чуприна ${ }^{1}$ \\ ${ }^{1}$ Киевский национальный университет имени Тараса Шевченко, \\ 01601 Киев, Украина \\ ${ }^{2}$ Институт фризико-органической химии и углехимии им. Л.М.Литвиненко НАН Украины, \\ 02160 Киев, Украина \\ ${ }^{3}$ Национальный университет пищевых технологий, \\ 01601 Киев, Украина \\ e-mail: ndav@univ.kiev.ua
}

Поступила в редакцию 22.03.2018 г.

В окончательной редакции 31.08.2018 г.

На основе сополимеров 4-((2-бром-4-нитрофенил)диазенил)фенилметакрилата созданы регистрирующие среды для поляризационной голографии и исследованы их свойства при записи голограмм плоского волнового фронта. Обнаружено, что при комнатной температуре скорость записи голограмм при перпендикулярной и параллельной поляризации записывающих лучей одинакова, а скорость релаксации голограмм выше в случае перпендикулярной ориентации поляризации записывающих лучей. Показано, что дифракционная эффективность голограмм не проявляет монотонной связи с температурой размягчения пленок.

DOI: $10.21883 /$ OS.2019.02.47203.85-18

\section{Введение}

Пленки полимерных композитов с мономерами азокрасителей или полимеров, содержащие азобензольные группы, проявляют фотоактивные свойства, и их можно использовать для создания электрооптических модуляторов света и регистрирующих сред (РС) для поляризационной голографии [1-5]. Принцип записи в таких средах основан на том, что при облучении линейно поляризованным светом в области поглощения трансизомеров в этих пленках появляется фотоиндуцированная оптическая анизотропия (ФИА), которая вызвана процессами транс-цис-изомеризации азобензольных групп. Реакция фотоизомеризации азобензольных хромофоров может вызвать конформационные изменения на молекулярном уровне, и в аморфных пленках могут образовываться устойчивые рельефы поверхности [515]. На основе тонких слоев полимеров, содержащих азобензольные группы, можно создать различные фотонные элементы, такие как дифракционные решетки, массивы микролинз, плазмонные датчики, просветляющие покрытия и наноструктурированные преобразователи поляризации света [1]. Голограммы, записанные на этих полимерах, стабильны при хранении ниже температуры размягчения $\left(T_{s}\right)$. Рельефы поверхности РС могут быть стерты путем нагревания образцов выше $T_{s}$, когда полимерная пленка переходит в вязкотекучее состояние и происходит релаксация („залечивание“, healing) этого рельефа. В настоящее время азополимеры и композиты на их основе находят практическое применение в РС. Однако в литературе в недостаточной мере рассмотрен вопрос оптимизации способов выбора молекулярных структур для создания РС. Целью ра- боты было экспериментальное исследование кинетики записи и релаксации голограмм плоского волнового фронта в РС на основе различных сополимеров 4((2-бром-4-нитрофенил)диазенил)фенилметакрилата при использовании записывающих лучей с параллельной и перпендикулярной поляризацией.

\section{Эксперимент}

Для исследований синтезированы сополимеры 1-4, структурные формулы которых имеют общий вид

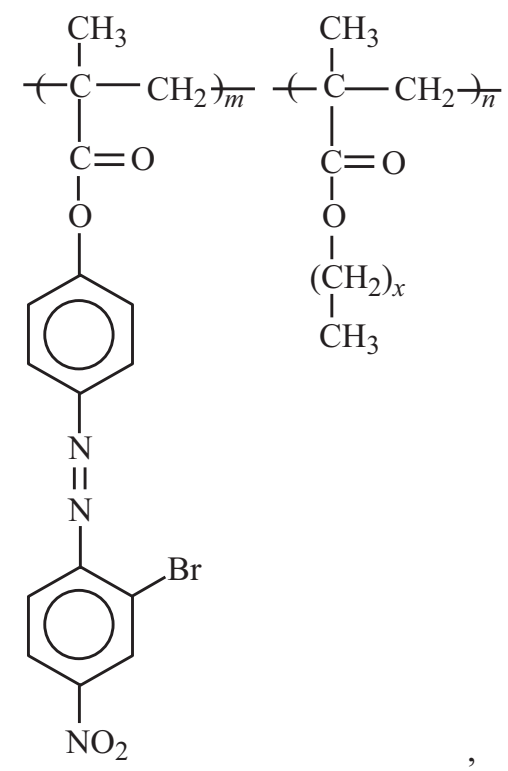

где $m: n=1: 2 ; x=0(\mathbf{1}) ; 3(\mathbf{2}) ; 5(\mathbf{3}) ; 9(\mathbf{4})$. 
Состав и структуру синтезированных сополимеров идентифицировали методами элементного анализа, ${ }^{1} \mathrm{H}$ NMR- и УФ спектроскопии. Сомономеры метилметакрилат в 1, бутилметакрилат в 2, гексилметакрилат в $\mathbf{3}$ и децилметакрилат в $\mathbf{4}$ определяют свойства полимерной матрицы для фотоактивных азобензольных хромофоров. Элементный анализ полученных соединений проводили на CHNOS-элементном анализаTope Elementar Gmbh „Vario Micro Cube“. ${ }^{1} \mathrm{H}$ NMRспектры полученных веществ снимали на ${ }^{1} \mathrm{H}$ NMRспектрометре Varian „Mercury-400“ в ДМСО- $d_{6}$ с внутренним стандартом тетраметилсиланом. Ряд сомономеров выбран исходя из того, что в их модельном ряду увеличивается длина гибкого метиленового фрагмента $\left(\mathrm{CH}_{2}\right)$ и это способствует понижению $T_{s}$ полимерной пленки (ПП). Температура размягчения $T_{s}$ ПП 1-4, которую измеряли по известной методике [16], составляет соответственно $86 \pm 2,79 \pm 2,65 \pm 2$ и $58 \pm 2{ }^{\circ} \mathrm{C}$.

Для исследований приготавливали образцы РС со свободной поверхностью ПП путем полива раствора сополимера в хлористом метилене на стеклянные подложки, сушки в течение $24 \mathrm{~h}$ в термошкафу при температуре $80^{\circ} \mathrm{C}$. Толщина ПП, измеренная с помощью интерференционного микроскопа МИИ-4, составила 1.8-2.0 $\mu \mathrm{m}$.

В образцах РC со свободной поверхностью ПП измеряли спектры оптической плотности $(D)$ и интенсивности $\left(I_{L}\right)$ фотолюминесценции на спектральновычислительном комплексе КСВИП-23 (ЛОМО). Эти же образцы РС использовали и для записи голограмм плоского волнового фронта. Использовали излучение $\lambda_{1}=532 \mathrm{~nm}$ твердотельного лазера с диодной накачкой и удвоением частоты при соотношении интенсивностей света в объектном $\left(I_{1}\right)$ и опорном $\left(I_{2}\right)$ лучах $1: 1$; пространственная частота $300 \mathrm{~mm}^{-1}$. Интенсивность света $I_{1}+I_{2}$ перед РС составляла $5 \cdot 10^{3} \mathrm{~W} / \mathrm{m}^{2}$. Запись голограмм проводили для параллельной $\left(\mathbf{e}_{1} \| \mathbf{e}_{2}\right)$ и перпендикулярной $\left(\mathbf{e}_{1} \perp \mathbf{e}_{2}\right)$ ориентаций электрических векторов падающих объектной $\left(\mathbf{e}_{1}\right)$ и опорной $\left(\mathbf{e}_{2}\right)$ световых волн. Величину дифракционной эффективности $(\eta)$ голограммы определяли по общепринятой методике [17] как отношение интенсивности света в -1-м порядке дифракции к интенсивности опорного луча $I_{2}$ (он же восстанавливающий луч в процессе считывания) для параллельной $\left(\mathbf{e}_{1} \| \mathbf{e}_{2}\right)$ и перпендикулярной $\left(\mathbf{e}_{1} \perp \mathbf{e}_{2}\right)$ ориентаций векторов электрических векторов записывающих световых волн (соответственно как $\eta_{\|}$и $\eta_{\perp}$ ). Измеряли зависимости $\eta_{\|}(t)$ и $\eta_{\perp}(t)$ от времени $(t)$ после начала и завершения экспонирования голограммы. Каждое новое измерение проводили на новом участке $\mathrm{PC}$, для исключения влияния предыдущего эксперимента (памяти о записи голограммы). Результаты измерений усредняли по трем образцам идентичных РС. Все измерения проведены при комнатной температуpe $20^{\circ} \mathrm{C}$.

\section{Результаты и их обсуждение}

На рис. 1 представлен нормированный спектр оптической плотности ПП с 1-4. В видимой области поглощение этих ПП определяется длинноволновым краем поглощения азохромофоров. Длинноволновый максимум поглощения вблизи длины волны света $\lambda \sim 440 \mathrm{~nm}$ можно пояснить наличием в структуре азобензольных хромофоров акцепторного заместителя $-\mathrm{NO}_{2}$, который понижает энергию возбужденных состояний. Фотолюминесценция этих же образцов при возбуждении лазером с $\lambda=532 \mathrm{~nm}$ не обнаружена, и $I_{L}=0$ на фоне шума.

В РС с ПП 1-4 зарегистрированы голограммы плоского волнового фронта как для случая $\mathbf{e}_{1} \| \mathbf{e}_{2}$, так и для случая $\mathbf{e}_{1} \perp \mathbf{e}_{2}$. На рис. $2, a-d$ представлены графики зависимости $\eta_{\|}(t)$, а на рис. $2, e-h-$ графики зависимости $\eta_{\perp}(t)$. В таблице приведены результаты измерений $\eta_{\|}$и $\eta_{\perp}$ после $2 \mathrm{~min}$ экспонирования голограммы в РС с ПП 1-4. Из представленных результатов видно, что в ряду РС с ПП 1-4 уменьшается $T_{s}$, но изменение квазистационарных значений $\eta_{\|}$и $\eta_{\perp}$, следовательно, и их зависимости от $T_{s}$, немонотонны. Наибольшая дифракционная эффективность наблюдается в РС для ПП 2 (рис. 3). Увеличение длины метиленовой цепи $(x>2)$ не только не приводит к увеличению $\eta_{\|}$и $\eta_{\perp}$, но даже вызывает значительное уменьшение эффективности голографической записи. При этом характерное время нарастания дифракционной эффективности до квазистационарного значения во всех случаях практически одинаково, а характерное время релаксации записи после выключения одного из записывающих лучей увеличивается. Последнее наиболее выражено в случае релаксации $\eta_{\perp}$ (рис. $\left.2, e-h\right)$. Из результатов, представленных на рис. 2, также видно, что для всех ПП 1-4 выполняется.соотношение $\eta_{\perp}>\eta_{\|}$, которое ранее обнаружили для РС на основе других азобензолсодержащих сополимеров и металлокомплексов на их основе $[4,5]$.

На рис. 4, а как пример представлена фотография экрана, на который спроецировано восстановленное

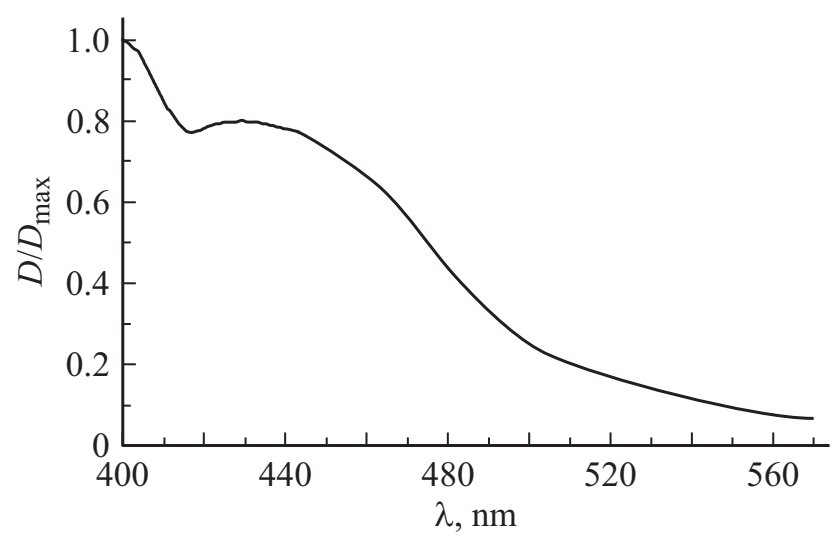

Рис. 1. Нормированный спектр поглощения РС с ПП 1-4. 

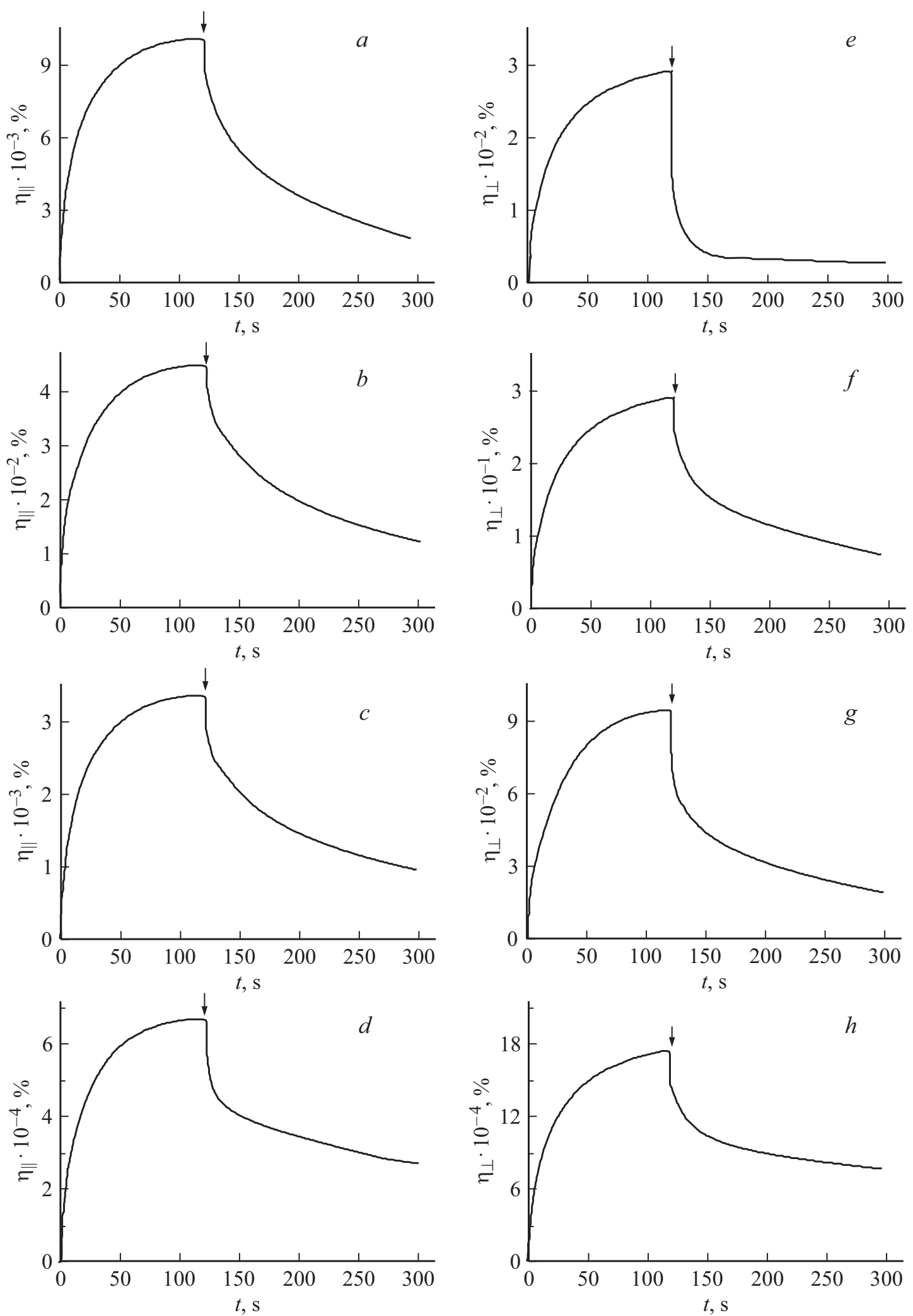

Рис. 2. Графики зависимости $\eta_{\|}(a-d)$ и $\eta_{\perp}(e-h)$ после начала $(t=0)$ записи голограммы и выключения объектного луча в момент времени $t=2 \min$ в образцах РС с ПП $1(a, e), 2(b, f), 3(c, g), 4(d, h)$. Момент выключения объектного луча отмечен вертикальной стрелкой, направленной вниз. 
изображение голограммы плоского волнового фронта в РС с ПП 2 после записи голограммы в течение $2 \min$ в случае $\mathbf{e}_{1} \perp \mathbf{e}_{2}$. Гладкость изображения свидетельствует о высоком значении отношения сигнал/шум, которое обеспечивается хорошими реологическими свойствами пленок сополимеров. На рис. $4, b, c$ представлены фотографии участка поверхности этого образца, полученные с помощью интерференционного микроскопа (микроинтерферометра) МИИ-4 в режиме светлого поля (рис. $4, b$ ) и в интерферометрическом режиме (рис. $4, c)$ в пределах $1 \mathrm{~min}$ после регистрации голограммы. На этих фотографиях хорошо различимы полосы, соответствующие образованному регулярному рельефу поверхности пленки величиной $\sim 0.2 \mu \mathrm{m}$. O малой зашумленности поверхности пленки наглядно свидетельствует также 3D-изображение этого участка поверхности ПП (рис. $4, d$ ), полученное в результате программной обработки фотографии рис. $4, b$. Подобные структуры на поверхности ПП образуются при записи рельефных амплитудных голограмм фототермопластическим способом на фотопроводящих полимерных пленках [16,17]; однородность таких структур обеспечивает высокие информационные характеристики РС.

Под действием линейно поляризованного света из области поглощения изомеров азобензольного хромофора происходит транс-цис-изомеризация азобензольных фрагментов. Считается [5-7], что именно перестройка полимерной матрицы ответственна за длительное хранение записи голограмм. При $\mathbf{e}_{1} \| \mathbf{e}_{2}$ и $\mathbf{e}_{1} \perp \mathbf{e}_{2}$ азобензольные группы, участвующие в фотоизомеризации, ориентируются в соответствующих направлениях, и появляются дополнительные деформирующие силы, дей-

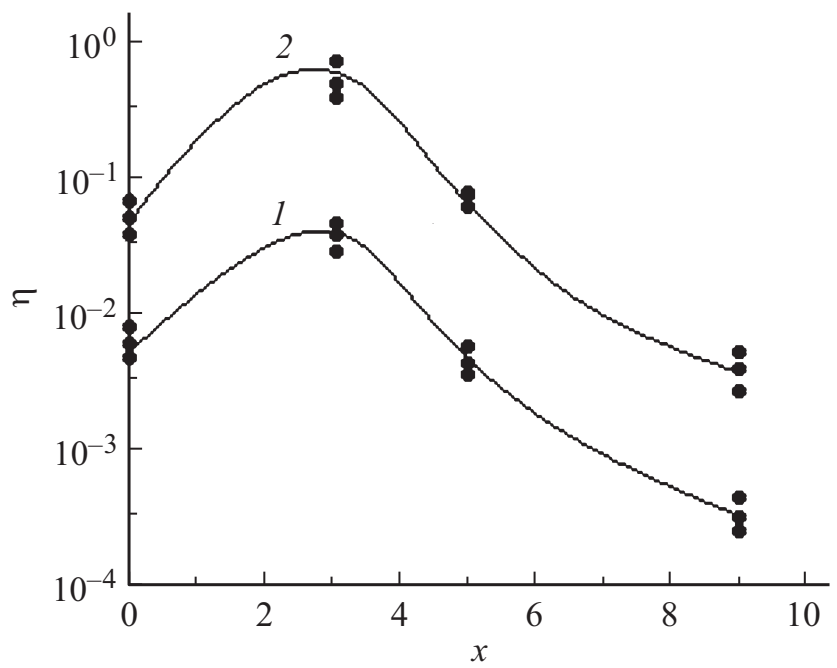

Рис. 3. Графики зависимости дифракционной эффективности $\eta_{\|}$(кривая 1) и $\eta_{\perp}$ (кривая 2) от числа $x$ метиленовых групп в гибком сополимере мономеров 1-4. Значения $\eta_{\|}$и $\eta_{\perp}$ измерены в трех идентичных образцах РС с ПП 1-4 в момент времени $t=2 \mathrm{~min}$ после начала записи голограммы плоского волнового фронта.
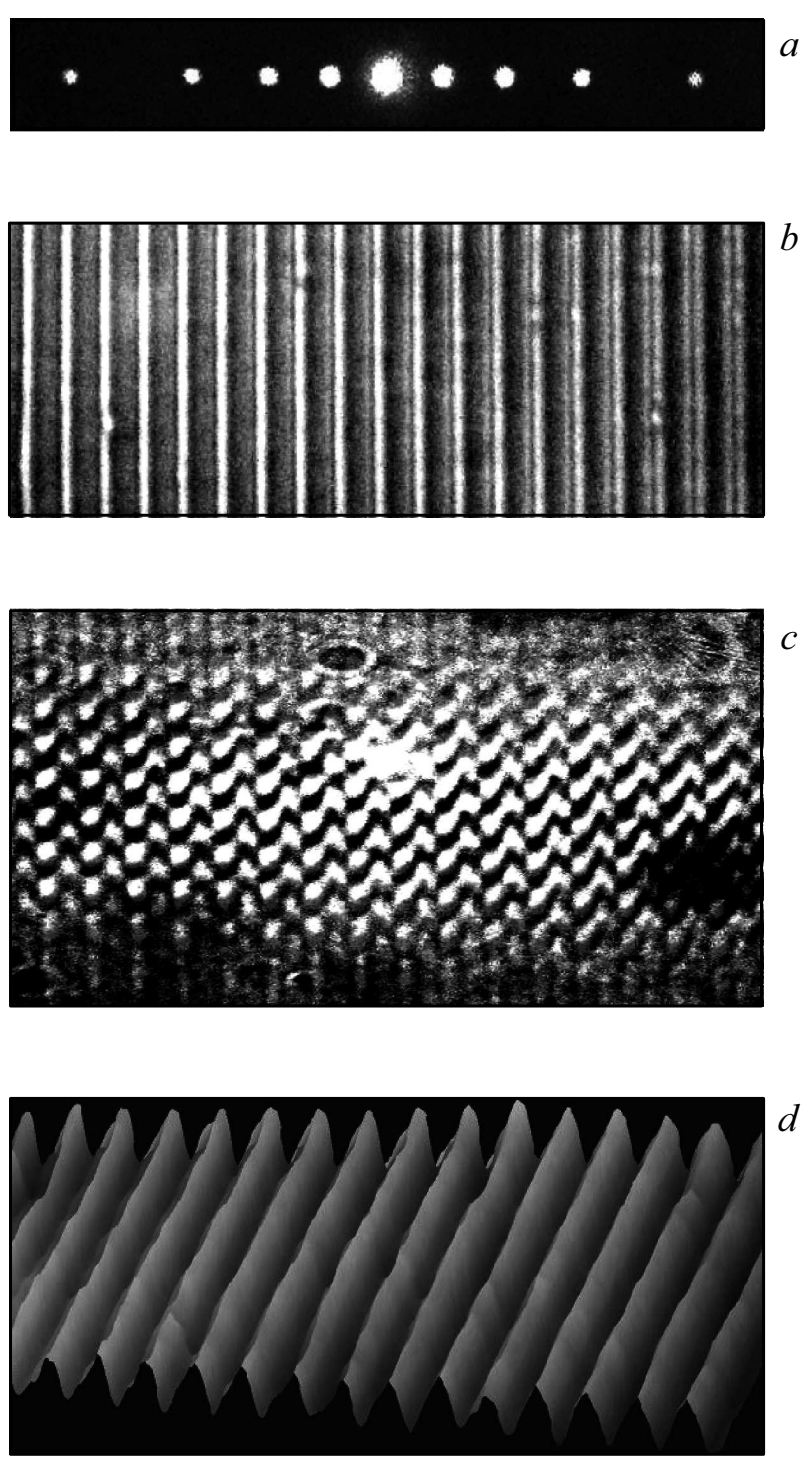

Рис. 4. $a-$ Фотография экрана, на который спроецировано восстановленное изображение голограммы плоского волнового фронта в РС с ПП 2 после записи голограммы в течение $2 \mathrm{~min} ; b-$ фотография участка поверхности этого образца, полученная с использованием интерференционного микроскопа МИИ-4 в режиме светлого поля в течение $1 \mathrm{~min}$ после регистрации голограммы; $c-$ фотография этого же участка поверхности образца, полученная в режиме интерференционного микроскопа; $d-3 \mathrm{D}$-изображение этого же участка свободной поверхности РС, полученное в результате программной обработки фотографии $b$.

ствующие на основную полимерную цепь, что приводит к формированию геометрического рельефа поверхности полимерной пленки в РС (рис. 4). Так как релаксация рельефа поверхности пленки происходит медленнее, чем релаксация скрытого голографического изображения в поляризационно чувствительных РС, то наличие такого рельефа в целом увеличивает время релаксации $\eta$. Так как в наших экспериментах при записи и восстановлении голограмм поляризация света с $\lambda=532 \mathrm{~nm}$ не 
изменялась, то разную кинетику релаксации $\eta_{\|}$и $\eta_{\perp}$, которая отображена на рис. $2, a-d$ и рис. $2, e-h$, нельзя объяснить простым изменением скорости цис-трансизомеризации. Если после регистрации голограммы вместо двух записывающих лучей остается только один луч опорной $\left(\mathbf{e}_{2}\right)$ световой волны, то ФИА в ПП может быть нивелирована за счет выравнивания концентрации цис-изомеров по всему освещаемому участку ПП. Тогда в случае предварительной записи при параллельной $\left(\mathbf{e}_{1} \| \mathbf{e}_{2}\right)$ ориентации электрических векторов световых волн возможно „залечивание“ рельефа ПП, и ранее сформировавшиеся периодические структуры в ПП исчезают быстрее, чем это исчезновение происходит естественным образом. Но если такой же механизм релаксации рельефа ПП применить и к объяснению релаксации $\eta_{\perp}$ в случае предварительной записи при перпендикулярной $\left(\mathbf{e}_{1} \perp \mathbf{e}_{2}\right)$ ориентации электрических векторов световых волн, то следовало бы ожидать такой же, но не гораздо меньшей ее скорости (рис. 2). Для объяснения наблюдаемых особенностей кинетики релаксации интерференционных полей, формирующих голограммы при различной поляризации записывающих лазерных пучков, и создаваемых этими полями распределений ориентаций азогрупп также нельзя привлечь механизмы, принятые для РС на основе пленок полиметилметакрилата, содержащих в качестве фоточувствительной добавки молекулы фенантренхинона [18]. Причина этого состоит в том, что принцип записи в таких РС основан на способности фенантренхинона образовывать фотопродукт, который присоединен к макромолекулам полимерной матрицы, и потому его подвижность крайне мала. Считается, что благодаря разнице в подвижности фенантренхинона и его фотопродукта реализуется постэкспозиционное усиление голограмм за счет диффузии молекул $Ф Х$, и именно это обеспечивает получение высокоэффективных и очень стабильных фазовых голограмм. При этом фотопревращения фенантренхинона в ПП приводят к изменению спектра поглощения РС таким образом, что они становится практически прозрачными в видимом диапазоне спектра [18]. В наших же РС механизм формирования ФИА имеет совершенно иную природу $[2,5]$. Поэтому мы вынуждены признать, что в настоящее время у нас нет адекватного объяснения наблюдаемым экспериментальным фактам в различии механизма релаксации $\eta_{\|}$ и $\eta_{\perp}$. Кроме того, не совсем ожидаема обнаруженная непропорциональная зависимость $\eta_{\|}$и $\eta_{\perp}$ от длины цепи $(x)$ гибкого компонента в структуре молекул сополимеров 1-4 (рис. 3). Ранее [5] было показано, что уменьшение жесткости полимерной матрицы сопровождается уменьшением $T_{s}$ и как следствие - улучшением условий для формирования рельефа поверхности ПП при записи голограмм. Именно такой эффект является определяющим для усиления рельефа поверхности ПП и дифракционной эффективности голографической записи в электрическом поле, создаваемом с помощью коронного разряда [5]. В случае ПП 1-4 уменьшение $T_{s}$ не приводит к возрастанию дифракционной эффективности (рис. 3), что должно стать предметом дальнейших исследований.

\section{Выводы}

Результаты экспериментальных исследований новых азобензолсодержащих сополимеров 1-4 подтверждают ранее наблюдаемое в РС соотношение $\eta_{\perp}>\eta_{\|}$. Это позволяет сделать вывод, что установленное соотношение характерно для всего класса РС с пленками азобензольных соединений, причем интересна замеченная особенность $\eta_{\perp} / \eta_{\|} \sim 3$. Для исследованного ряда сополимеров наибольшая дифракционная эффективность достигается в РС с ПП 2, для которых $x=2$ и $T_{s}=79 \pm 2{ }^{\circ} \mathrm{C}$. Последнее свидетельствует о том, что при выборе фоточувствительных материалов для поляризационночувствительных РC параметр $T_{s}$ не отражает оптимальные характеристики РС. Полученные результаты представляют практический интерес при разработке и создании новых регистрирующих сред для поляризационной голографии.

\section{Список литературы}

[1] Барачевский В.А. // Опт. и спектр. 2018. Т. 124. № 3. C. 371; Barachevsky V.A. // Opt. and Spectrosc. 2018. V. 124. N 3. P. 373-407. doi 10.1134/S0030400X18030062

[2] Nikolova L., Ramanujam P.S. Polarization Holography. Cambridge, UK, Cambridge University Press, 2009.

[3] Bian S., Williams J.M., Kim D.Yu., Li L., Balasubramanian S., Kumar J., Tripathy S. // J. Appl. Phys. 1999. V. 86. N 8. P. 4498.

[4] Davidenko N.A., Savchenko I.A., Davidenko I.I., Popenaka A.N., Shumeluk A.N., Bedarev V.A. // Technical Physics. 2007. V. 52. N 4. P. 451.

[5] Davidenko N.A., Davidenko I.I., Pavlov V.A., Chuprina N.G., Tarasenko V.V., Studzinsky S.L. // J. Appl. Phys. 2017. V. 122. P. 013101-1-6.

[6] Priimagi A., Shevchenko A.J. // Polymer Sci. Part B: Polymer Phys. 2014. P. 163.

[7] Natansohn A., Rochon P. // Chem. Rev. 2002. V. 102. N 11. P. 4139.

[8] Simonov A.N., Uraev D.V., Kostromin S.G., Shibaev V.P., Stakhanov A.I. // Laser Physics. 2002. V. 12. P. 1294.

[9] Emoto A., Uchida E., Fukuda T. // Polymers. 2012. V. 4. P. 150.

[10] Karageorgiev P., Neher D., Schulz B., Stiller B., Pietsch U., Giersig M., Brehmer L. // Nature Materials. 2005. V. 4. P. 699.

[11] Garrot D., Lassailly Y., Lahlil K., Boilot J.P., Peretti J. // Appl. Phys. Lett. 2009. V. 94. P. 033303-1-3.

[12] Zhou J., Yang J., Ke Y., Shen J., Zhang Q., Wang K. // Optical Materials. 2008. V. 30. P. 1787.

[13] Hackel M., Kador L., Kropp D., Schmidt H.-W. // Adv. Mater. 2007. V. 19. P. 227.

[14] Davidenko N.A., Davidenko I.I., Pavlov V.A., Chuprina N.G., Kravchenko V.V., Tarasenko V.V., Studzinsky S.L., Mokrinskaya E.V., Tonkopieva L.S. // Optik. 2018. V. 158. P. 1308. 
[15] Davidenko N.A., Davidenko I.I., Pavlov V.A., Chuprina N.G., Mokrinskaya E.V., Tarasenko V.V., Tonkopieva L.S., Kravchenko V.V. // Optical Materials. 2018. V. 76. P. 169.

[16] Schwetlick $K$. Organicum. WILEY- VCH Verlag GmbH, D69469 Weinheim, 2001.

[17] Collier R.J., Burckhart C.B., Lin L.H. Optical Holography. NY. and London: Academic Press, 1973.

[18] Veniaminov A.V., Mahilny U.V. // Opt. Spectrosc. 2013. V. 115. N 6. P. 906-930. doi 10.1134/S0030400X13120199 